\title{
A study on phase separation in InGaN/GaN multi-quantum wells
}

\author{
M. Y. Kim,* H. J. Lee*, Y. J. Yoon*, Y. Yoon*, S .H. Park*, B.K Kim*, J. W. Han*
}

*Samsung Electro-Mechanics Co. LTD, 314, Maetan3-Dong Yeongtong-Gu, Suwon Gyounggi-Do, 443-743, South Korea

Phase separation in InGaN/GaN multi-quatum wells (MQWs) grown with various annealing time is studied for obtaining the high brightness green LED. For this purpose, transmission electron microscopy (TEM), and photoluminescence (PL) are used.

InGaN/GaN MQWs for the Green LED with high Indium composition up to $30 \%$ are grown at $800-900{ }^{\circ} \mathrm{C}$ by metal organic chemical vapor deposition (MOCVD) and annealed during 0, 5, 12.5 minutes at $1000^{\circ} \mathrm{C}$. It is found that the phase separation in $\mathrm{InGaN} / \mathrm{GaN}$ multi-quantum wells under the condition of annealing for 5minutes is severe according to PL spectrum and indium ratio map. It is directly obtained indium concentration map images with energy filtered transmission electron microscopy (EFTEM) which can be interpreted as indium compositional fluctuation in Fig 1. The PL intensities of MQWs with annealing for 5 minutes increased when compared to MQWs prepared without annealing at $1000{ }^{\circ} \mathrm{C}$ and The PL spectra separated blue and green emission peaks as the result of indium phase separation in Fig. 2. As the annealing time increases, the emission peak shows a blueshift in Fig 2. The presence of indium clustering with high indium composition results in high luminescence efficiency. It is likely to see the recombination center of excitons localized in indium clustering regions.

\section{References}

[1] Y. Nakukawa et al. Phys. Rev. B 55. (1997) 1938R.

[2] R. Singh, O. Doppalapudi, T. D. Moustakas, L. T. Romanao, APL 70(90) (1997) 3.

[3] T. M. Smeeton, M. K. Kappers, J. S. Barnard, M. E.Vickers, C. J. Humphery. phys. stat. sol. (b) 240, No. 2, (2003) 297-300.

[4] S. Chichibu, T. Asuhata, T. Sato, S. Nakamura, APL. 69 (1996) 4188.

[5] M. E.Vickers, M. J. Kappers and T. M. Smeeton, E. J. Thrush, J.S. Barnard and C.J. Humphreys, J. Appl. Phys. 94(3) (2003) 1565-1574. 

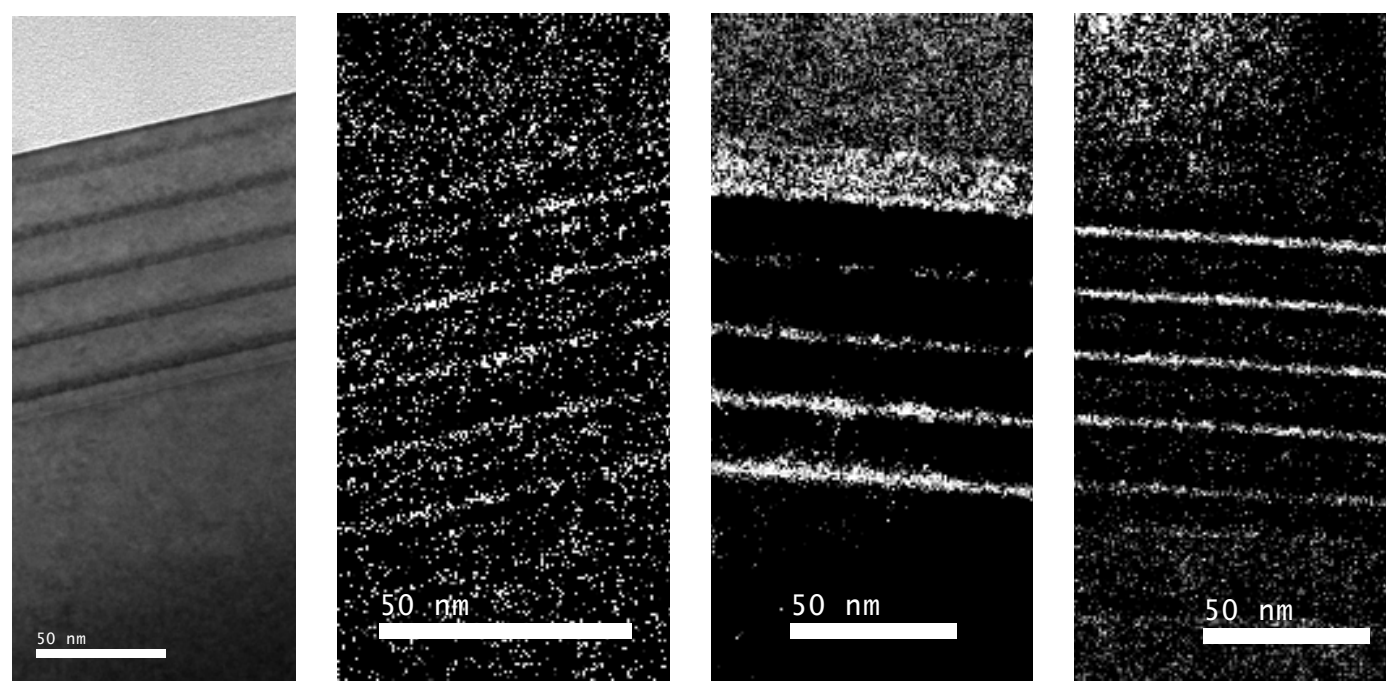

Fig 1. Element mapping results of indium with EFTEM (a) as grown (b) annealing at $1000^{\circ} \mathrm{C}$ for 5minutes (c) for 12.5 minutes.
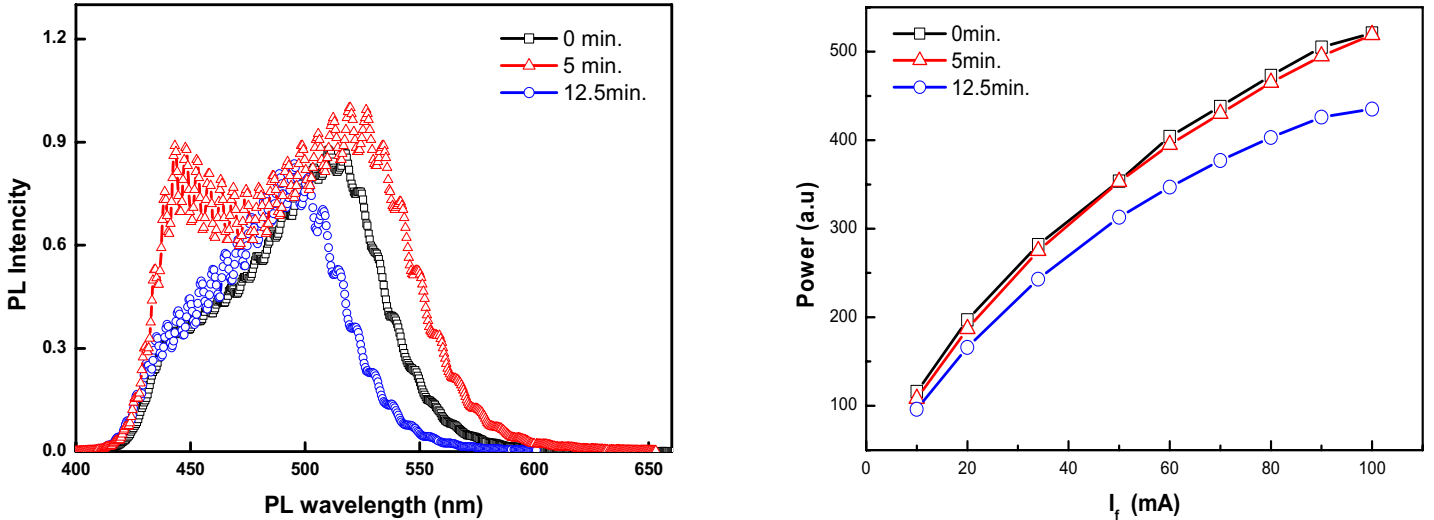

Fig 2. Photoluminescence spectra at RT of $\mathrm{InGaN} / \mathrm{GaN}$ multi quantum wells of annealing $1000^{\circ} \mathrm{C}$ for $0,5,12.5$ minutues.

Fig 3. Light output power versus injection current of InGaN/GaN green LEDs at room temperature of annealing at $1000^{\circ} \mathrm{C}$ for $0,5,12.5$ minutes. 